\title{
ESTIMATION OF EVAPOTRANSPIRATION FOR IRRIGATED ARTIFICIAL GRASSLANDS IN TYPICAL STEPPE AREAS USING THE METRIC MODEL
}

\author{
WANG, J. ${ }^{1,2}-$ LI, H. P. ${ }^{1,2}-$ LU, H. Y. ${ }^{1,2^{*}}-$ ZHANG, R. Q. ${ }^{1,2}-$ CAO, X. S ${ }^{2}$-TONG, C. F. ${ }^{2}-$ ZHENG, H. X. ${ }^{2}$ \\ ${ }^{I}$ State Key Laboratory of Simulation and Regulation of Water Cycle in River Basin, China \\ Institute of Water Resources and Hydropower Research, Beijing, China \\ ${ }^{2}$ Institute of Water Resources for Pastoral Area, China Institute of Water Resources and \\ Hydropower Research, Hohhot, China \\ *Corresponding author \\ e-mail: haiyuan_lu@126.com
}

(Received $5^{\text {th }}$ May 2019; accepted $16^{\text {th }}$ Jul 2019)

\begin{abstract}
Irrigated artificial grasslands can help in achieving a large amount of forage in the Inner Mongolia typical steppe areas of China. However, developing irrigated artificial grasslands requires the consumption of water resources, and also affects the hydrological cycle. In this study, mapping evapotranspiration at high resolution with internalized calibration (METRIC) model has been used to estimate regional evapotranspiration during the crop growth season (from May to September) in irrigated artificial grasslands in 2011. The results were verified based on the data obtained from eight monitoring points of irrigated silage maize farms using water balance method, with a mean relative error value of $13.8 \%$. The average evapotranspiration for irrigated artificial grasslands during the crop growth season is $611.42 \mathrm{~mm}$. To further analyze the consumption of local water resources, concept of groundwater consumption (GW) is proposed. The GW value for irrigated artificial grasslands during the crop growth season was estimated to be $457.96 \mathrm{~mm}$; the GW values at each of these farms, including Woyuan cow, Maodeng, Baiyinxile, Hezhongmumin, exceeded $400 \mathrm{~mm}$. The results show that these areas, which exhibit high water consumption face difficulties in water resource management, particularly when there is no external water supply.
\end{abstract}

Keywords: remote sensing, precipitation, Landsat images, underlying surface, water balance

\section{Introduction}

Irrigated artificial grasslands are arable lands planted with artificial herbage in pastoral areas. It is supplemented by modern irrigation facilities to achieve a high forage yield. Irrigated artificial grasslands can produce a large amount of forage in the Inner Mongolia typical steppe areas of China (Niu and Jiang, 2004). The development and construction of irrigated artificial grasslands on a significant scale in the areas with better water resources can improve the yield of high-quality forage and resolve the problem of livestock forage shortage. This can also play an important role in improving the carrying capacity of pastures, thereby reducing the pressure on natural steppes and promoting water-forage-livestock system balance (Lu et al., 2016, 2018). However, irrigated artificial grasslands in the Inner Mongolia typical steppe areas are restricted by arid climate. In most cases, irrigation can only be obtained via pumping groundwater, because these areas are mainly distributed in the semi-arid region of Eurasia (Tong et al., 2004), in which the vast majority of the rivers are seasonal inland rivers (Batnasan, 2003), among which hydrological and geographical features are characterized by precipitation rarely flowing into rivers or groundwater. Evapotranspiration (ET) is the main mode of water vapor exchange between the underlying surface and atmosphere (Yamanaka et al., 2007). This hydrographic feature has led to a lack of local surface 
water resources, which in turn makes it difficult for agricultural development. The Xilin River is the only seasonal inland river in the basin, and supplies water for various purposes, except irrigation. Therefore, the water required for irrigating artificial grasslands is sourced from local groundwater, in addition to precipitation. Owing to limited precipitation, crops grown on artificial grasslands must be irrigated. Pumping groundwater to satisfy the crop growth needs of irrigated artificial grasslands bring benefits to the regional economy, but consumes a large amount of groundwater, affecting the hydrological cycle in the steppe areas. The advantages and disadvantages of this water consumption need to be determined. Therefore, accurate monitoring of the water consumption for irrigated artificial grasslands, especially local groundwater consumption, can help determine regional irrigation water consumption and water resource management decisions (Liou and Kar, 2014; Pedro-Monzonís et al., 2015; Numata et al., 2017; Talsma et al., 2018).

Many ET monitoring and estimation methods have emerged with related theoretical research. These include the water balance method, aerodynamics methods, and scintilla meter measurements (Bowen, 1926; Thornthwaite, 1948; Howell et al., 1991; Rana and Katerji, 2000). These methods have displayed the ability to describe the characteristic rules of the ET processes at micro and farmland scales in detail (Liou and Kar, 2014). In addition, they have also provided important references and basic information for water vapor exchanges on underlying surfaces, decision-making with respect to farmland irrigation, comprehensive water resource management, and so forth (Long and Singh, 2013; French et al., 2015; Xu et al., 2015). However, in terms of regional ET estimation, owing to fluctuations in weather conditions and the dynamic nature of water-heat transfer processes (Gao et al., 2008), it has been determined that these traditional point-scale monitoring methods and approaches cannot fully reflect the actual characteristics of spatial changes in ET (Su et al., 2003; Cai et al., 2009; Monteith and Unsworth, 2013; Taherparvar and Pirmoradian, 2018). It has been determined that remote sensing technology can offer a new approach for regional ET estimation. Because of the spatial continuity and large span characteristics of remote sensing, the water that is consumed during ET can be derived directly, without the need to quantify other complex hydrological processes (Trezza et al., 2013).

ET models using remote sensing technology have been developed in recent years, including empirical methods and mechanism methods. Many achievements in theory innovation and method techniques have been presented (Khand et al., 2017). Among these proposed methods, two-source energy balance (TSEB), surface energy balance index (SEBI), simplified surface energy balance index (S-SEBI), surface energy balance algorithm for land (SEBAL), mapping evapotranspiration at high resolution with internalised calibration (METRIC) model have been widely used to calculate regional ET based on the theory of energy balance (Menenti, 1993; Norman et al., 1995; Bastiaanssen et al., 1998; Roerink et al., 2000; Su, 2002; Allen et al., 2007; Yang et al., 2010). As a typical representative of estimating regional ET by using remote sensing, the METRIC model is a variant of the SEBAL model that implements the residual method to calculate regional ET (Spiliotopoulos et al., 2017; Zamani Losgedaragh and Rahimzadegan, 2018). The METRIC model has been successfully used in many areas, as a physical model for high-precision estimation of regional ET (Allen et al., 2007, 2013; Morton et al., 2013; Paço et al., 2014; Reyes-González et al., 2017; Spiliotopoulos et al., 2017). 
The objective of this paper is to use high-resolution Landsat images as an example to estimate the regional ET for irrigated artificial grasslands in the Inner Mongolia typical steppe areas by the METRIC model. Based on the development model of current groundwater by irrigated artificial grasslands, groundwater consumption (GW) and its law in the crop growth season are analyzed to accurately simulate and monitor the hydrological cycle in the Inner Mongolia typical steppe areas.

\section{Materials and methods}

\section{Study area}

The Xilin River Basin is a typical inland river basin in the Inner Mongolia typical steppe areas of China (Chen, 2002). The basin, with an area of approximately $11,172 \mathrm{~km}^{2}\left(115.53^{\circ}-117.25^{\circ} \mathrm{E}, 43.41^{\circ}-44.63^{\circ} \mathrm{N}\right)$, has a typical continental temperate semi-arid climate. In accordance with the statistical data of the Xilinhot Station detailed on the National Meteorological Data website, the multi-year (period 1971-2011) average precipitation, ET from the water surface, air temperature, and wind speed are $263.5 \mathrm{~mm}, 1,904 \mathrm{~mm}, 3{ }^{\circ} \mathrm{C}$, and $3.4 \mathrm{~m} \mathrm{~s}^{-1}$, respectively. The average precipitation gradually decreases from the southeast to northwest (Sheng, 2017) (Fig. 1).

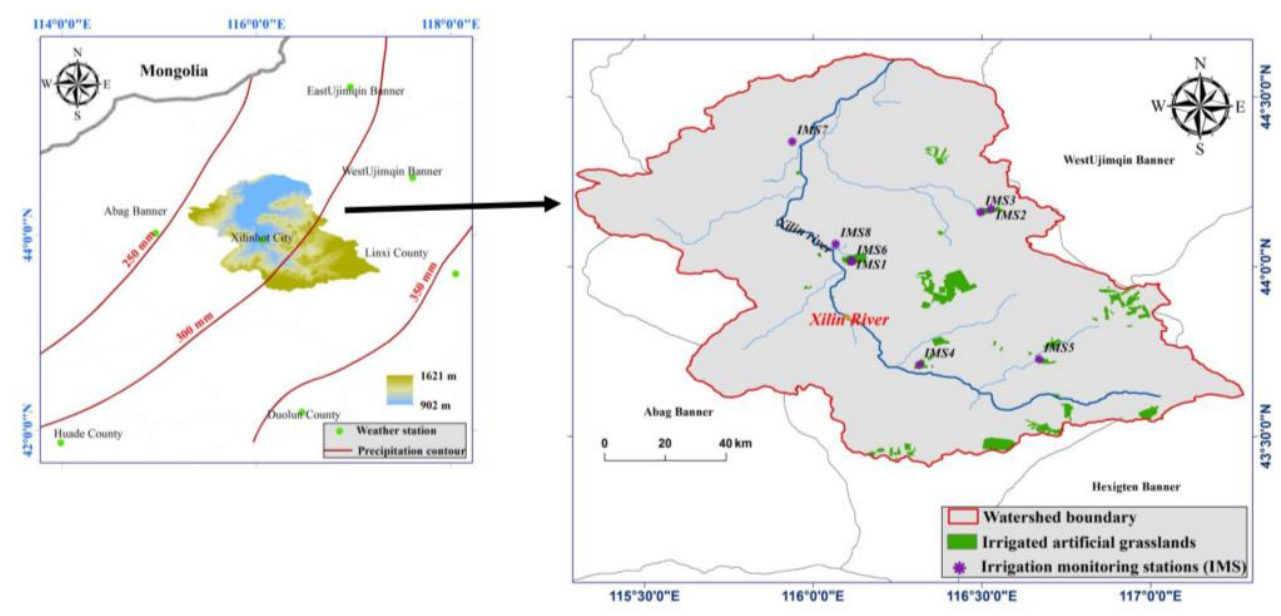

Figure 1. Distribution for irrigated artificial grasslands in Xilin River Basin

The planted area of the irrigated artificial grasslands in 2011 was approximately $257.3 \mathrm{~km}^{2}$ (Fig. 1). The crops were silage maize $\left(128.6 \mathrm{~km}^{2}\right)$, potato $\left(96.5 \mathrm{~km}^{2}\right)$, alfalfa $\left(25.8 \mathrm{~km}^{2}\right)$, and green millet $\left(6.4 \mathrm{~km}^{2}\right)$. The management departments included co-ops (such as Hezhongmumin farm) and companies (Woyuan cow farm, Maodeng farm, Baiyinxile farm). Because of the effective accumulated temperature restriction, the crop growth season is from May to September every year with an irrigation quota of 400$700 \mathrm{~mm}$. These crops bring benefits to the regional economy while consumes a large amount of water. In addition, amid limited precipitation, the crops grown on artificial grasslands must be irrigated. However, there is only one seasonal inland river in the basin, the Xilin River that supplies water for various purposes except irrigation. Therefore, the water required for irrigating artificial grasslands is sourced from local groundwater, apart from precipitation. Irrigation has a great impact on local water resource management. 


\section{Data}

\section{Landsat images}

In this study, Landsat-5 and Landsat-7 images were chosen to estimate ET. In the data bands of these images, visible light and near-infrared bands have a high spatial resolution of $30 \mathrm{~m}$, which satisfies the validation requirements for the spatial accuracy of ET estimation results in this study. In combination with the cloud cover of the study area, the effective 8-day sunshine data during the crop growth season (from May to September) of 2011 (day of the year from 121 to 273) were used to calculate the longtime scale of ET (Table 1). All the data were obtained from the United States Geological Survey (http://glovis.usgs.gov/).

Table 1. Landsat-5/7 TM data information (PATH 124, ROW 29/30)

\begin{tabular}{c|c|c|c}
\hline Date & $\begin{array}{c}\text { Day of the year } \\
\text { (DOY) }\end{array}$ & $\begin{array}{c}\text { Cloud coverage } \\
(\boldsymbol{\%})\end{array}$ & Sensor \\
\hline $2011 / 04 / 12$ & 102 & 1 & Landsat-5 \\
$2011 / 05 / 14$ & 134 & 8 & Landsat-5 \\
$2011 / 05 / 22$ & 142 & 23 & Landsat-7 \\
$2011 / 08 / 02$ & 214 & 0 & Landsat-5 \\
$2011 / 08 / 10$ & 222 & 0 & Landsat-7 \\
$2011 / 09 / 11$ & 254 & 0 & Landsat-7 \\
$2011 / 09 / 19$ & 262 & 2 & Landsat-5 \\
$2011 / 10 / 05$ & 278 & 6 & Landsat-5 \\
\hline
\end{tabular}

\section{Meteorological data}

Meteorological data included air temperature, wind velocity, water vapor pressure, solar radiation, humidity, and precipitation in the seven weather stations of East Ujimqin Banner, Abag Banner, Huade County, West Ujimqin Banner, Xilinhot City, Linxi County, and Duolun County (Fig. 1). Among these, the air temperature data were used to calculate the surface temperature and net radiation by the METRIC model; the wind velocity data to calculate the aerodynamic resistance by the METRIC model; and the water vapor pressure data to calculate atmospheric transmittance and surface albedo by the METRIC model (Bastiaanssen et al., 1998; Allen et al., 2007). Other parameters such as solar radiation and humidity were used to calculate reference crop evapotranspiration $\left(\mathrm{ET}_{0}\right)$ by FAO Penman-Monteith equation (Allen et al., 1998). The meteorological data were obtained from the National Meteorological Data Information Center (http://data.cma.cn/).

\section{Evapotranspiration measurement data}

The ET measurement data were obtained from the eight irrigation monitoring stations (IMS) (Fig. 1). The crop cultivated in the monitoring station was silage maize. The average volumetric weight of soil was $1.54-1.82 \mathrm{~g} \mathrm{~cm}^{-3}$ for a thickness varying from 0 to $100 \mathrm{~cm}$. The field water holding capacity $\left(\theta_{f}\right)$ was $14.3 \%-19.0 \%$ (accounting for the dry soil weight), and the buried depth of the groundwater level was over $3 \mathrm{~m}$. Based on water balance method, the water consumption data of the silage maize growth period were calculated to evaluate the results of the METRIC model. 


\section{Methods}

\section{METRIC model}

The SEBAL model is the theoretical basis of the METRIC model (Bastiaanssen et al., 1998a, b; Allen et al., 2007). In the model, by considering the interference of the underlying surface elevation, slope gradient, slope direction, and other factors, the surface information obtained through remote sensing are converted to surface albedo, surface emissivity, vegetation index, roughness length, surface temperature, and other characteristic parameters. This model is combined with the meteorological observational data of the underlying surfaces to calculate the regional ET (Allen et al., 2007; GonzálezDugo et al., 2012). The theoretical equation is given as follows:

$$
L E=R_{n}-G-H
$$

where LE is the latent energy consumed by ET; $R_{n}$ is the net radiation; $G$ is the soil heat flux; and $H$ is the sensible heat flux. Each energy component is generally expressed in $\mathrm{W}$ $\mathrm{m}^{-2}$.

\section{(1) Net radiation}

$R_{n}$ denotes the difference in the whole-band radiation quantity between the downward projection from the sky (including the sun and the atmosphere) and the upward projection from the Earth's surface (including soil, plants, and water). This parameter represents the main power source for the energy and water transmission of the underlying surfaces (Allen et al., 2007):

$$
R_{n}=(1-\alpha) K_{\text {in }}+\left(L_{\text {in }}-L_{\text {out }}\right)-(1-\varepsilon) L_{\text {in }}
$$

where $\alpha$ is the surface albedo (dimensionless); $K_{\text {in }}$ is the incoming short-wave radiation $\left(\mathrm{W} \mathrm{m}^{-2}\right) ; L_{\text {in }}$ is the incoming long-wave radiation $\left(\mathrm{W} \mathrm{m}^{-2}\right) ; L_{\text {out }}$ is the outgoing long-wave radiation $\left(\mathrm{W} \mathrm{m}^{-2}\right)$; and $\varepsilon$ is the broad-band surface emissivity (dimensionless).

(2) Soil heat flux

$G$ refers to the part of energy stored in vegetation and soil due to conduction, and its changes are mainly affected by net radiation, surface temperature and the vegetation cover on underlying surfaces. For the comprehensive analysis in this study, the achievements of Wright and Bastiaanssen are referred as follows (Wright, 1982; Bastiaanssen et al., 1998):

$$
G=\frac{T_{s}-273.15}{\alpha}\left(0.0038 \alpha+0.0074 \alpha^{2}\right) \times\left(1-0.978 N D V I^{4}\right) R_{n}
$$

where $T_{s}$ is the surface temperature $(\mathrm{K})$; and NDVI is the normalized difference vegetation index (dimensionless).

(3) Sensible heat flux

$H$ is a parameter, describing the exchange of energy between land surfaces and atmosphere, in which energy is transferred from the Earth's surface to the atmosphere 
through convection or conduction. The calculation of $H$ in the METRIC model is based on the following assumptions: dry and wet pixels exist in the study area; and there is a linear relationship between the temperature difference $d T\left(d T=T_{1}-T_{2}\right)$ at $z_{1}$ and $z_{2}$ above the height of the zero-plane displacement and $T_{s}$. The space interpolation of the meteorological data on the underlying surfaces can then be avoided. Furthermore, the errors due to $T_{s}$ are corrected to calibrate the calculation results of each pixel in remote sensing imaging through the elevation, slope gradient, and slope direction:

$$
H=\rho_{a i r} c_{p} \frac{d T}{r_{a}}
$$

where $\rho_{\text {air }}$ is the air density $\left(\mathrm{kg} \mathrm{m}^{-3}\right)$; $c_{p}$ is the air specific heat capacity at a constant pressure $\left(1,004 \mathrm{~J} \mathrm{~kg}^{-1} \mathrm{~K}^{-1}\right)$; and $r_{a}$ is the aerodynamic resistance between two near surface heights, which has been calculated by the Monin-Obukhov theory (Allen et al., 2007); The calculation equations is given as follows:

$$
\begin{gathered}
d T=a T_{s, \text { adtum }}+b \\
T_{s, \text { adtum }}=T_{s}+0.0065 \Delta Z
\end{gathered}
$$

where $a$ and $b$ are empirical constants; $T_{s, a d t u m}$ is the surface temperature adjusted to a common elevation data for each image pixel by using a digital elevation model and customized lapse rate $(\mathrm{K})$; For non-planar areas, it is necessary to use the numerical elevation difference $\Delta Z$ for the corrections; and $\Delta Z$ is the difference between the elevation of each pixel and the reference elevation $(\mathrm{m})$.

Dry and wet pixels are the two extreme pixels required for calculation using the METRIC model. Dry pixels refer to the dry idle wasteland or bare land areas without vegetation cover; these pixels are characterized by high temperature and almost zero ET (Bastiaanssen et al., 1998; Allen et al., 2007). In this study, dry pixels approximately satisfied LE $\approx 0$. The dry end of the $d T$ function is estimated by rearranging Equation 4 for a selected dry pixel in the image:

$$
d T_{d r y}=\frac{\left(R_{n}-G\right)_{d r y} r_{a d r y}}{\rho_{a i r d r y} c_{p}}
$$

where $r_{a} d r y$ is $r_{a}$ computed for the roughness and stability conditions of the dry pixel; and $\rho_{\text {air dry }}$ is $\rho_{\text {air }}$ calculated at the dry pixel.

Wet pixels refer to areas with adequate water supply, dense vegetation growth, low temperatures and potential ET levels in the remote sensing images (Bastiaanssen et al., 1998; Allen et al., 2007). These could include completely covered areas or open water masses with good plant growth. For the wet pixels, $H \approx 0$ is usually set in the SEBAL model, and such $H$ values are considered in the METRIC model (Allen et al., 2007).

$$
d T_{\text {wet }}=\frac{\left(R_{n}-G-H\right)_{w e t} r_{\text {awet }}}{\rho_{\text {airwet }} c_{p}}
$$


where $r_{a}$ wet is ra computed for the roughness and stability conditions of the wet pixel; $\rho_{\text {air wet }}$ is $\rho_{\text {air }}$ calculated at the wet pixel.

The distribution of $d T$ is obtained by extracting the information regarding the dry and wet pixels (de la Fuente-Sáiz et al., 2017). The values for $a$ and $b$ in Equation 5 are estimated from these two pairs of $d T$ and associated $T_{s, \text { adtum. }}$.

$$
\begin{gathered}
a=\frac{d T_{d r y}-d T_{\text {wet }}}{T_{s, a d t u m, d r y}-T_{s, a d t u m, w e t}} \\
b=d T_{d r y}-a T_{s, a d t u m d r y}
\end{gathered}
$$

\section{(4) Surface parameters}

Surface parameters contain $\alpha, \varepsilon, \mathrm{NDVI}, T_{s}$ and Momentum roughness length $\left(Z_{o m}\right)$ which are crucial in the atmospheric-surface interaction and consequently affect the ET estimation. Among them, $\alpha$ is computed by integrating band reflectance within the short-wave spectrum using a weighting function (Allen et al., 2007); $\varepsilon$ is computed using an empirical equation (Tasumi, 2003); NDVI is the ratio of the differences in reflectivity for the near-infrared band and red band to their sum (Allen et al., 2007); $T_{s}$ is computed the single window algorithm proposed by Qin (Qin et al., 2010); $Z_{o m}$ for each image is specified by the corresponding NDVI (Allen et al., 2007).

(5) Long-time scale of the daily evapotranspiration

In addition, it is assumed that the instantaneous ET ratio $\left(E F_{\text {inst }}, E F_{\text {inst }}=\mathrm{LE}_{\text {inst }} /\left(R_{n^{-}}\right.\right.$ $\left.G)_{\text {inst }}\right)$ is equal to the daily ET ratio $\left(E F_{d}, E F_{d}=\mathrm{LE}_{\mathrm{d}} /\left(R_{n}-G\right)_{\mathrm{d}}\right)$, when the instantaneous ET is used to calculate the daily ET (ET $)$ (Bastiaanssen et al., 1998a, b). In this study, in order to estimate long-time scale of the daily ET, the daily reference ET ratio $\left(\mathrm{ET}_{\mathrm{r}} \mathrm{F}\right.$ is the ratio between $\mathrm{ET}_{\mathrm{d}}$ and daily $\mathrm{ET}_{0}, \mathrm{ET}_{\mathrm{r}} \mathrm{F}=\mathrm{ET}_{\mathrm{d}} / \mathrm{ET}_{0}$ ) of the eight DOYs were calculated, and the crop growth season was divided into seven intervals (Table 1). Each interval consisted of two DOYs of effective sunshine satellite images. Thereafter, by assuming that the $\mathrm{ET}_{\mathrm{r}} \mathrm{F}$ change between two adjacent effective sunshine days is linearly correlated with the DOY, interpolation was used to calculate the daily ET during the period:

$$
\begin{aligned}
E T_{d, D O Y} & =(c \times D O Y+d) \times E T_{0, D O Y} \\
c & =\frac{E T_{r} F_{n}-E T_{r} F_{m}}{D O Y_{n}-D O Y_{m}} \\
d & =E T_{r} F_{n}-c \times D O Y_{n}
\end{aligned}
$$

where $c$ and $d$ are constants; $\mathrm{ET}_{\mathrm{d}, \mathrm{DOY}}$ and $\mathrm{ET}_{0, \mathrm{DOY}}$ are the daily $\mathrm{ET}$ and $\mathrm{ET}_{0}$ between two adjacent effective sunshine days respectively; and $\mathrm{ET}_{\mathrm{r}} \mathrm{F}_{\mathrm{n}}$ and $\mathrm{ET}_{\mathrm{r}} \mathrm{F}_{\mathrm{m}}$ are the $\mathrm{ET}_{\mathrm{r}} \mathrm{F}$ when the DOY is $n$ and DOY is $m$, respectively $\left(\right.$ DOY $_{n}: 278,262,254,222,214,142,134$; DOY $_{m}$ : 262,254,222,214,142,134,102). 
Evapotranspiration of silage maize at irrigation monitoring stations by the METRIC model

The evapotranspiration of silage maize consumed by the crops were calculated using the water balance method as follows (Kang, 2007):

$$
E T_{I M S}=P_{a}+I-L+K-\Delta W
$$

where $\mathrm{ET}_{\mathrm{IMS}}$ is the ET value of IMS; $P_{a}$ is the effective precipitation; $I$ denotes irrigation; $L$ is the amount of deep leakage; and $K$ is the groundwater recharge amount. Because of the fact that the buried depth of the groundwater was greater than $3 \mathrm{~m}$, as per the observations of a buried negative pressure meter, groundwater recharge was observed to be minimal; therefore, $K \approx 0 . \Delta W$ represents the variation in planned soil moisture layer during the growth cycle of silage maize. All the above parameters are in units of mm (Fig. 2a).

\section{Groundwater consumption for irrigated artificial grasslands}

Each irrigated artificial grassland is regarded as an independent land unit. According to the "one piece of sky corresponding to one piece of land," a land unit is divided into three spatial structure components: atmosphere, irrigated artificial grasslands, and groundwater. The inflow of water to irrigated artificial grasslands during the crop growth season includes $P_{a}$ from the atmosphere, and $K$ and $I$ from groundwater. Water consumed by irrigated artificial grasslands includes ET from irrigated artificial grasslands to the atmosphere, and $L$ from the irrigated artificial grasslands to groundwater. It is considered that the local groundwater supplements the unsaturated zone of the irrigated artificial grasslands. This water is still stored in the irrigated artificial grasslands; thus, it is classified as internal consumption of local water resources. The rest of the water separates from the irrigated artificial grasslands by ET, which is the net consumption and defined as the local groundwater consumption. From another perspective, for the amount of water consumed by the irrigated artificial grasslands on the underlying surface, and aside from the $P_{a}$ supply of the atmosphere, the remainder of the water is sourced from groundwater. Therefore, GW is estimated using the difference between ET and $P_{a}$ (Fig. $2 b$ ).

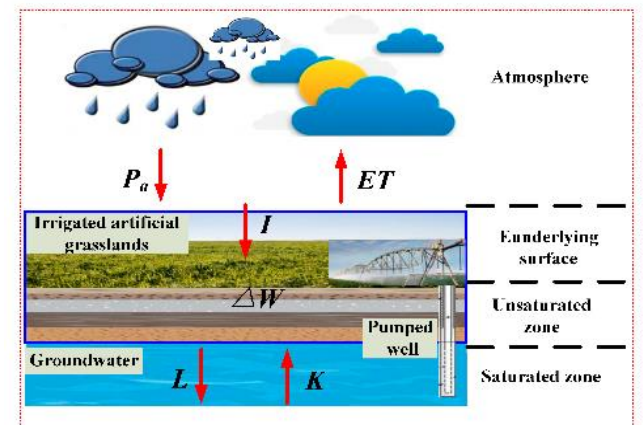

a

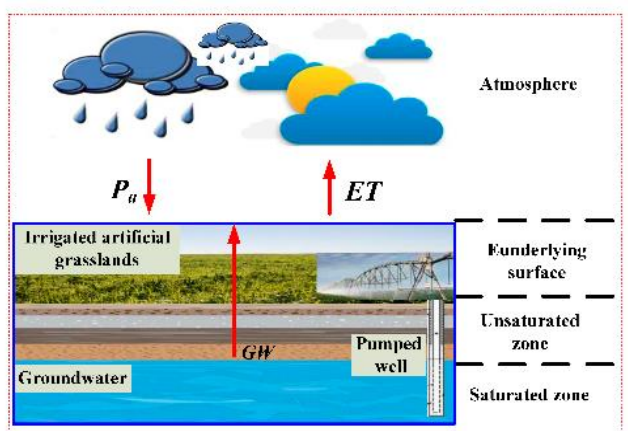

b

Figure 2. Water balance for irrigated artificial grasslands: (a) evapotranspiration of silage maize based on water balance; (b) groundwater consumption for irrigated artificial grasslands based on water balance 
The GW was calculated using the water balance for irrigated artificial grasslands as follows:

$$
\begin{aligned}
& G W=E T-P_{a} \\
& P_{a}=\sum P_{s} \times \sigma
\end{aligned}
$$

where $P_{s}$ denotes a single rainfall; and $\sigma$ is the effective precipitation coefficient, which is determined from the measured data. For areas without measured data, the following values can be referred to as: $\sigma=0$ when $P_{s}<5 \mathrm{~mm} ; \sigma=1.0$ when $5<P_{s} \leq 50 \mathrm{~mm}$; $\sigma=0.7-0.8$ when $P_{s}>50 \mathrm{~mm}$ (Kang, 2007).

The value of $\mathrm{GW}$ is the net groundwater consumption of the irrigated artificial grasslands in the Inner Mongolia typical steppe areas (Fig. 2b). By calculating the value of GW during the crop growth season, it is possible to visually reflect the amount of local water consumed by the irrigated artificial grasslands.

\section{Comparison of ET $T_{M E T R I C}$ and $E T_{I M S}$}

ET METRIC was accurately estimated by computing the mean absolute error (MAE) and mean relative error (MRE). The values of MAE and MRE were computed as follows (Mayer and Butler, 1993):

$$
\begin{gathered}
M A E=\frac{\sum_{i=1}^{n}\left|E T_{\text {METRIC }}-E T_{\text {IMS }}\right|}{n} \\
M R E=\frac{1}{n} \sum_{i=1}^{n}\left|\frac{E T_{M E T R I C}-E T_{I M S}}{E T_{I M S}}\right| \times 100 \%
\end{gathered}
$$

where ETMETRIC is the estimated ET by the METRIC model; and $n$ is the number of observations.

\section{Results and discussion}

\section{Estimated accuracy of evapotranspiration by METRIC model}

All the crops grown at the eight monitoring stations were silage maize, with an average growth period of 97 days. The irrigation methods included central pivot sprinkler irrigation (CPSI), drip irrigation (DI), low-pressure pipeline irrigation (LPPI), and semi-fixed irrigation (SFI). The average actual water consumption of silage maize during the growth period was determined to be $445.10 \mathrm{~mm}$ using Equation 14. The average value of ET METRIC of silage maize in the eight stations during the growth period was determined to be $428.73 \mathrm{~mm}$, in which MAE $=16.37 \mathrm{~mm}$ and $\mathrm{MRE}=13.8 \%$. By summarizing the previous research results, Kalma reviewed the various estimation methods of different remote sensing ET, and observed that when compared with the ground-based ET measurement value, the majority of the relative errors ranged from $15.0 \%$ to $30.0 \%$ (Kalma et al., 2008). Therefore, in this study it was believed that the accuracy of long-term scale ET estimation was reasonable and consistent with the 
previous research related conclusions (Allen et al., 2011; Lian and Huang, 2015) (Table 2).

The estimation results summarized in Table 2 show that the MRE of CPSI and DI is lower than that of SFI and LPPI by approximately $32.1 \%$ and the cause of this phenomenon was analyzed in this study. The ET $_{\text {METRIC }}$ is the regional comprehensive water consumption of the underlying surface. Within the corresponding time period, the researchers randomly sampled the field water consumption data, and CPSI and DI was employed to reflect the actual situation of field water consumption more objectively than SFI and LPPI, because historical measured data are applied to confirm that the

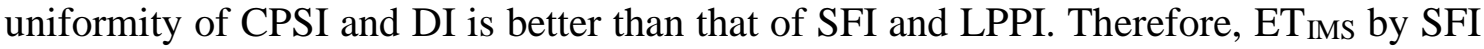
and LPPI may not accurately reflect the regional comprehensive water consumption as CPSI and DI do.

Table 2. Comparison of $E T_{M E T R I C}$ and $E T_{I M S}$ during the growth period of silage maize

\begin{tabular}{l|c|c|c|c|c|c|c|c|c|c}
\hline No. & $\begin{array}{c}\text { Irrigation } \\
\text { type }\end{array}$ & $\begin{array}{c}\text { Growth cycle } \\
(\mathbf{D O Y}-D O Y)\end{array}$ & $\begin{array}{c}\boldsymbol{P}_{\boldsymbol{a}} \\
(\mathbf{m m})\end{array}$ & $\begin{array}{c}\boldsymbol{I} \\
(\mathbf{m m})\end{array}$ & $\begin{array}{c}\boldsymbol{L} \\
(\mathbf{m m})\end{array}$ & $\begin{array}{c}\boldsymbol{\Delta} \boldsymbol{W} \\
(\mathbf{m m})\end{array}$ & $\begin{array}{c}\mathbf{E} \mathbf{T}_{\text {IMS }} \\
(\mathbf{m m})\end{array}$ & $\begin{array}{c}\text { ET } \\
(\mathbf{m m})\end{array}$ & $\begin{array}{c}\text { Absolute } \\
\text { error } \\
(\mathbf{m m})\end{array}$ & $\begin{array}{c}\text { Relative } \\
\text { error } \\
(\boldsymbol{\%})\end{array}$ \\
\hline IMS1 & CPSI & $140-243$ & 133.40 & 450.00 & $/$ & 36.38 & 547.03 & 511.26 & 35.77 & 6.5 \\
IMS2 & CPSI & $145-243$ & 127.30 & 337.50 & $/$ & 5.28 & 459.52 & 470.32 & 10.80 & 2.3 \\
IMS3 & CPSI & $145-243$ & 127.30 & 375.00 & $/$ & 35.48 & 466.83 & 490.83 & 24.00 & 5.1 \\
IMS4 & CPSI & $152-243$ & 127.30 & 405.00 & $/$ & 33.62 & 498.69 & 469.55 & 29.14 & 5.8 \\
IMS5 & CPSI & $152-243$ & 127.30 & 375.00 & $/$ & 41.00 & 461.31 & 479.02 & 17.72 & 3.8 \\
IMS6 & DI & $156-250$ & 127.30 & 142.00 & 1.73 & -10.54 & 278.11 & 308.53 & 30.42 & 10.9 \\
IMS7 & LPPI & $145-243$ & 127.30 & 90.00 & $/$ & -8.46 & 225.76 & 311.47 & 85.71 & 38.0 \\
IMS8 & SFI & $145-243$ & 127.30 & 495.00 & $/$ & -1.26 & 623.56 & 388.86 & 234.70 & 37.6 \\
\hline
\end{tabular}

\section{Evapotranspiration for irrigated artificial grasslands in the crop growth season}

The value of ET for the irrigated artificial grasslands in the Xilin River Basin during the crop growth season varied from 241.99-741.55 mm, with an average of $611.42 \mathrm{~mm}$, standard deviation of $80.73 \mathrm{~mm}$, and daily average ET intensity of $4.0 \mathrm{~mm} \mathrm{~d}^{-1}$ (Fig. $3 a$ ). Because of the combined effects of climatic conditions, irrigation water volume, soil texture, vegetation cover, and other factors, the estimation of ET shows obvious spatial differentiation characteristics. For example, the water consumption in the CPSI areas were significantly higher than that in the surrounding areas that are not effectively irrigated (Fig. 3b-e).

\section{Groundwater consumption for irrigated artificial grasslands and its law for different periods}

\section{Precipitation and effective precipitation for irrigated artificial grasslands}

The values of $P$ and $P_{a}$ for the irrigated artificial grasslands, which were determined to be $207.18 \mathrm{~mm}$ and $153.46 \mathrm{~mm}$ in 2011, respectively (Table 3) were obtained from precipitation statistics of the seven weather stations. The Linxi County and Duolun County stations in the southeast part of the basin presented the greatest precipitation, while the Abag Banner station in the northwest part of the basin showed the least. $P$ values during the crop growth season show a parabolic change of first increasing, and then decreasing, with the maximum appearing in July. 


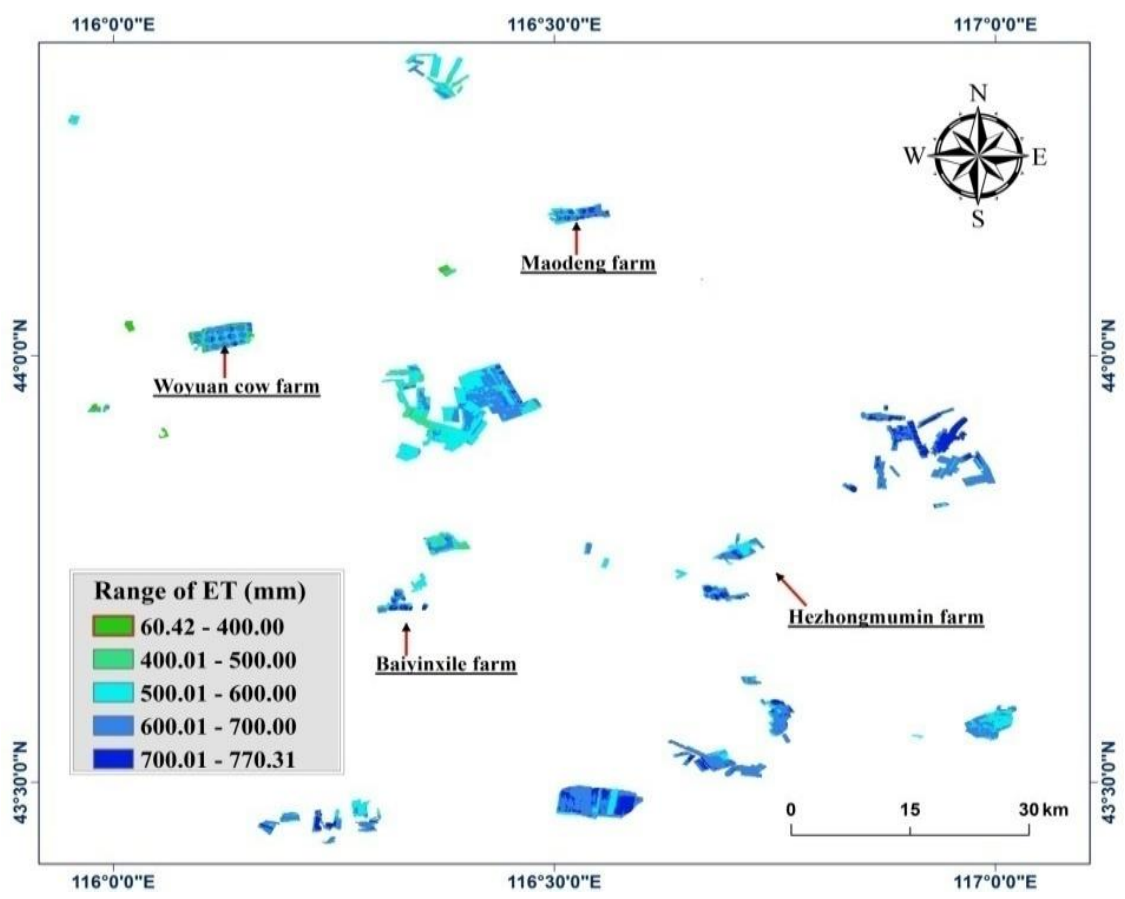

(a) ET $_{\text {METRIC values for irrigated artificial grasslands }}$

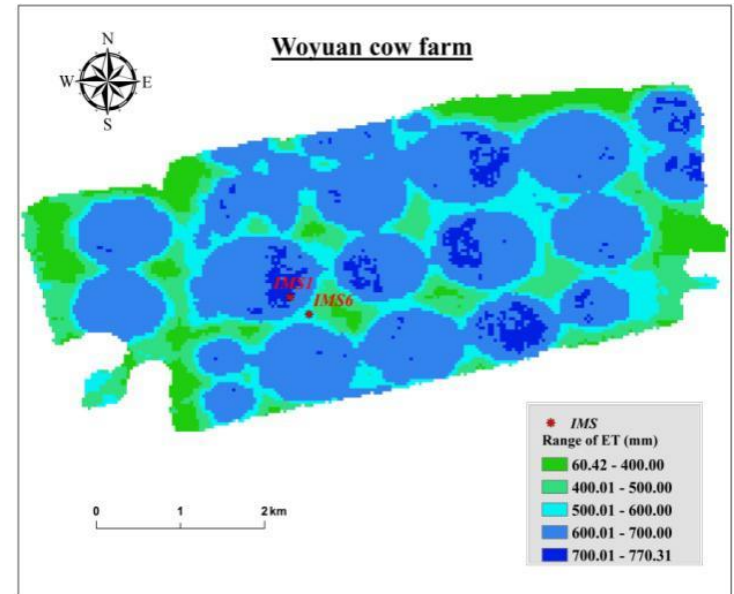

(b) ETMETRIC values of Woyuan cow farm

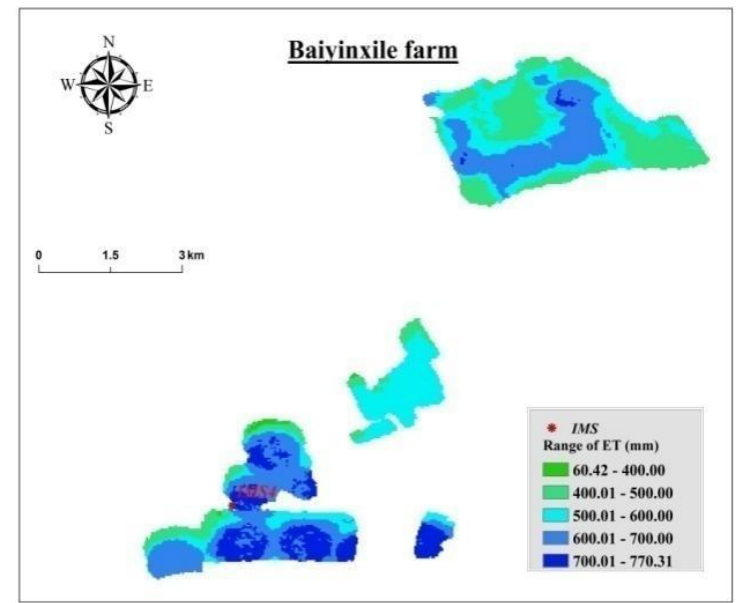

(d) ETMETRIC values of Baiyinxile farm

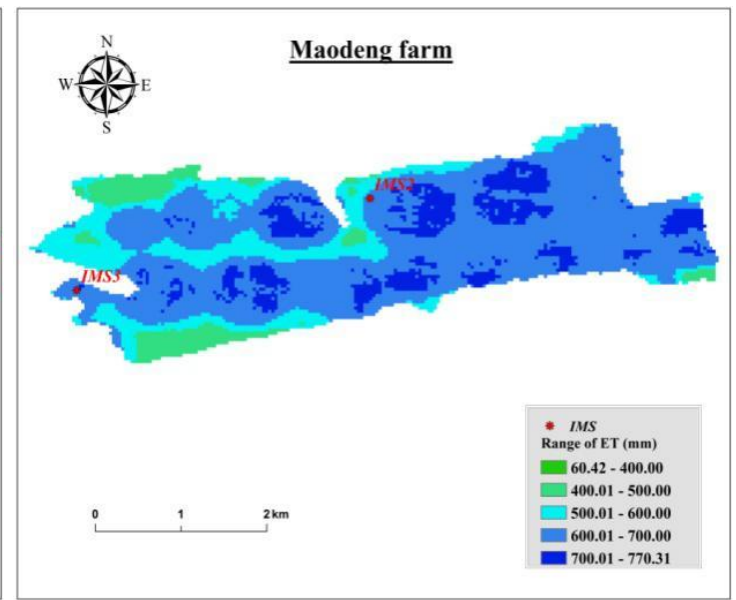

(c) ETMETRIC values of Maodeng farm

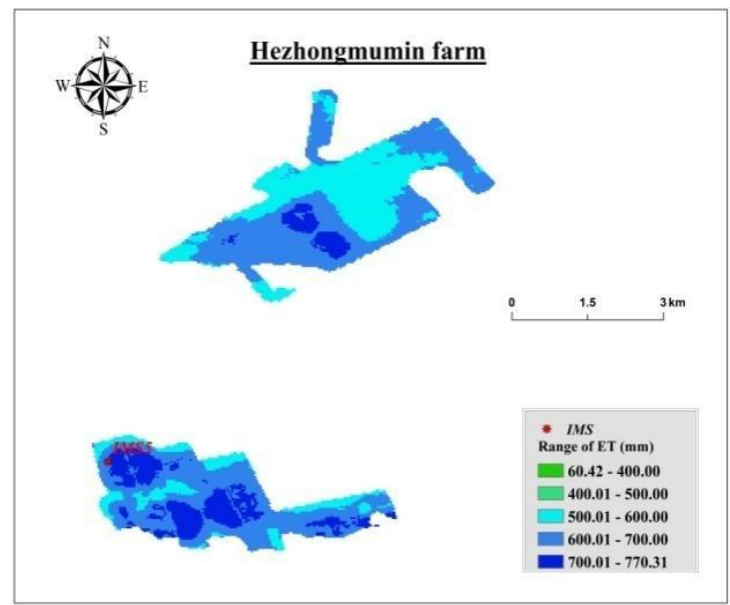

(e) ETMETRIC values of Hezhongmumin farm

Figure 3. ET $T_{M E T R I C}$ values for irrigated artificial grasslands in the crop growth season 
Table 3. Accumulation of precipitation and effective precipitation in the crop growth season in 2011

\begin{tabular}{c|c|c|c|c|c|c|c}
\hline $\begin{array}{c}\text { Weather station } \\
(\mathbf{l o c a t i o n})\end{array}$ & $\begin{array}{c}\boldsymbol{P} \\
\boldsymbol{P}_{\boldsymbol{a}}\end{array}$ & $\begin{array}{c}\text { May } \\
(\mathbf{m m})\end{array}$ & $\begin{array}{c}\text { Jun. } \\
(\mathbf{m m})\end{array}$ & $\begin{array}{c}\text { Jul. } \\
(\mathbf{m m})\end{array}$ & $\begin{array}{c}\text { Aug. } \\
(\mathbf{m m})\end{array}$ & $\begin{array}{c}\text { Sep. } \\
(\mathbf{m m})\end{array}$ & $\begin{array}{c}\text { Accumulation } \\
(\mathbf{m m})\end{array}$ \\
\hline EastUjimqin Banner & $P$ & 19.2 & 21.9 & 68.7 & 34.0 & 21.9 & 165.7 \\
$\left(116.97^{\circ} \mathrm{E}, 45.52^{\circ} \mathrm{N}\right)$ & $P_{a}$ & 6.1 & 16.0 & 51.0 & 22.5 & 13.2 & 108.8 \\
\hline Abag Banner & $P$ & 23.0 & 30.2 & 50.5 & 4.9 & 10.2 & 118.8 \\
$\left(114.95^{\circ} \mathrm{E}, 44.02^{\circ} \mathrm{N}\right)$ & $P_{a}$ & 9.4 & 12.9 & 39.7 & 0.0 & 5.9 & 67.9 \\
\hline Huade County & $P$ & 36.1 & 45.0 & 45.7 & 42.7 & 9.8 & 179.3 \\
$\left(114.00^{\circ} \mathrm{E}, 1.90^{\circ} \mathrm{N}\right)$ & $P_{a}$ & 32.6 & 26.1 & 21.8 & 37.6 & 0.0 & 118.1 \\
\hline WestUjimqin Banner & $P$ & 29.2 & 27.7 & 230.2 & 4.3 & 7.9 & 299.3 \\
$\left(117.60^{\circ} \mathrm{E}, 44.58^{\circ} \mathrm{N}\right)$ & $P_{a}$ & 15.0 & 20.9 & 202.1 & 0.0 & 0.0 & 238.0 \\
\hline Xilinhot City & $P$ & 23.9 & 57.1 & 77.2 & 18.1 & 3.6 & 179.9 \\
$\left(116.07^{\circ} \mathrm{E}, 43.95^{\circ} \mathrm{N}\right)$ & $P_{a}$ & 6.1 & 51.0 & 64.3 & 12.0 & 0.0 & 133.4 \\
\hline Linxi County & $P$ & 10.5 & 58.4 & 263.8 & 31.9 & 12.6 & 377.2 \\
$\left(118.07^{\circ} \mathrm{E}, 43.60^{\circ} \mathrm{N}\right)$ & $P_{a}$ & 0.0 & 50.1 & 187.6 & 29.5 & 5.4 & 272.6 \\
\hline Duolun County & $P$ & 25.9 & 75.7 & 83.8 & 19.4 & 16.4 & 221.2 \\
$\left(116.47^{\circ} \mathrm{E}, 42.18^{\circ} \mathrm{N}\right)$ & $P_{a}$ & 8.5 & 73.4 & 64.2 & 18.4 & 10.7 & 175.2 \\
\hline
\end{tabular}

$P$ and $P_{a}$ of the irrigated artificial grasslands were calculated on the basis of the inverse distance weighted interpolation method (Fig. 4). The results indicate that the corresponding spatial distribution trend of precipitation decreases from southeast to northwest (Fig. 4a), which is consistent with the trend of precipitation statistics in China for many years (Huang et al., 2011; Sheng, 2017). Thus, it can be concluded that the interpolation results are valid.

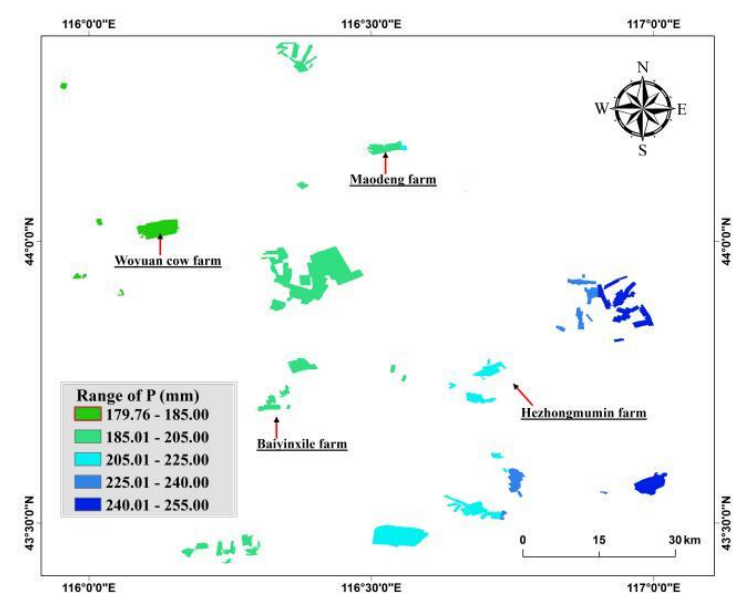

(a)

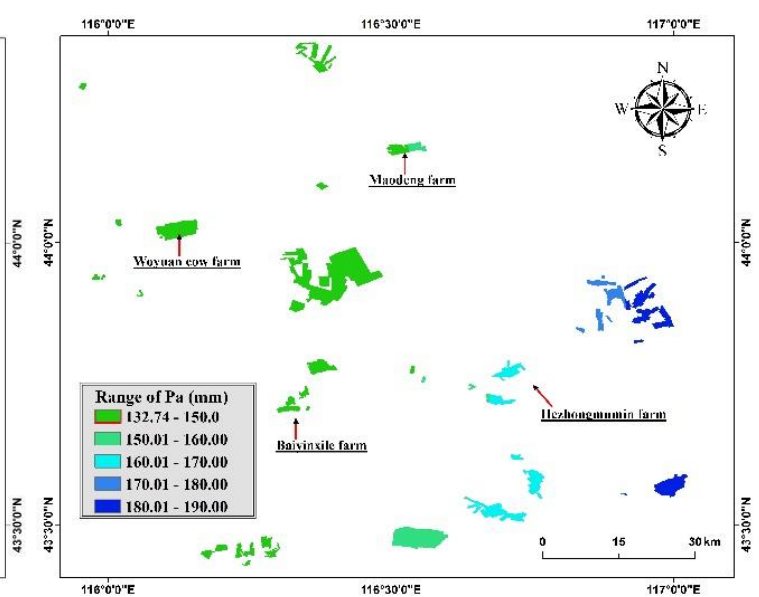

(b)

Figure 4. Precipitation and effective precipitation values of irrigated artificial grasslands in the crop growth season: (a) precipitation of irrigated artificial grasslands; $(b)$ effective precipitation of irrigated artificial grasslands

\section{Groundwater consumption for irrigated artificial grasslands}

The value of GW of the irrigated artificial grasslands during the crop growth season in 2011 was calculated to be $457.86 \mathrm{~mm}$ by using Equation 15. According to statistics, 
the planted area of the irrigated artificial grasslands in 2011 was approximately $257.3 \mathrm{~km}^{2}$, and the equivalent water volume was approximately 118 million $\mathrm{m}^{3}$. In addition, it can be observed that at Woyuan cow farm, Maodeng farm, Baiyinxile farm, and Hezhongmumin farm, the value of GW of groundwater exceeded $400 \mathrm{~mm}$ (Fig. $5 \mathrm{~b}$ $e$ ). The local water consumption in these areas was significantly higher than other areas, making high water consumption areas.

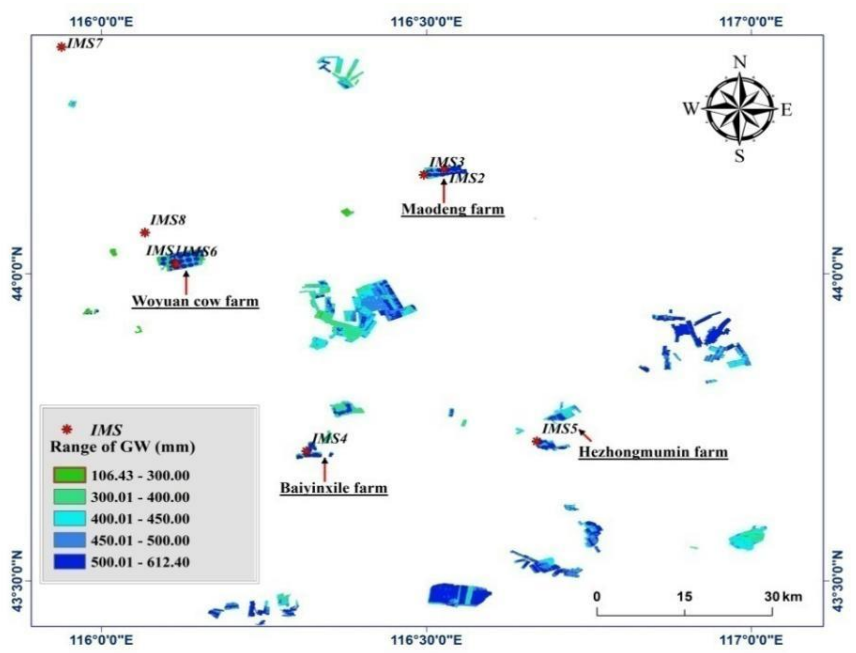

(a) GW values of Xilin River Basin

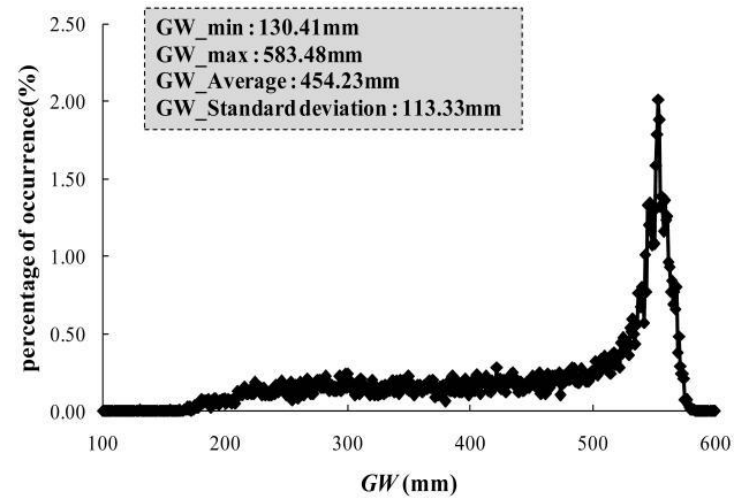

(b) GW values of Woyuan cow farm

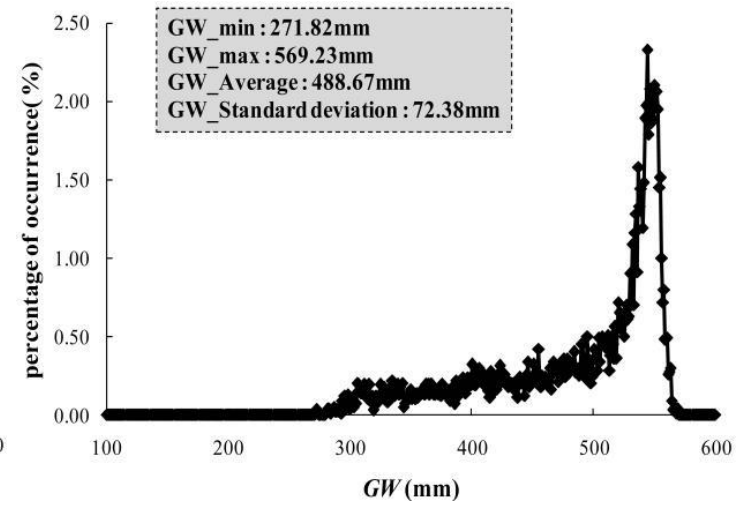

(c) GW values of Maodeng farm

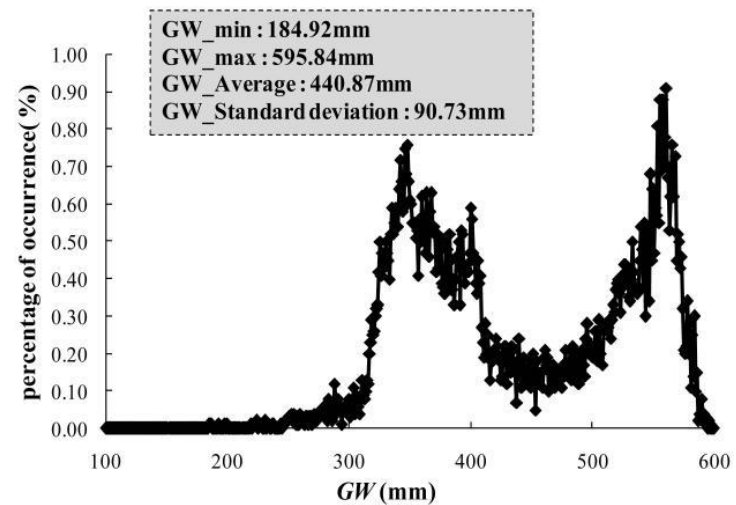

(d) GW values of Baiyinxile farm

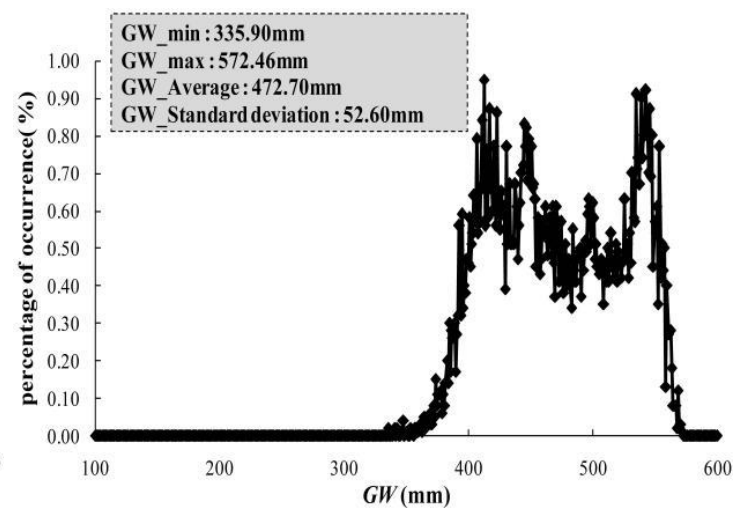

(e) GW values of Hezhongmumin farm

Figure 5. Groundwater consumption values for irrigated artificial grasslands during the crop growth season 


\section{Laws of groundwater consumption in different periods}

The crop growth season of the irrigated artificial grasslands is divided into five periods by month, with an accumulated 153 days (Table 4). In accordance with the Landsat images and meteorological data, the values of ET, $P_{a}$, and $\mathrm{GW}$ in different periods were obtained (Table 4; Fig. 6).

Table 4. Groundwater consumption of the irrigated artificial grasslands in different periods (all parameters are in units of $\mathrm{mm}$ )

\begin{tabular}{c|c|c|c|c|c|c}
\hline & May & Jun. & Jul. & Aug. & Sep. & Accumulation \\
\hline DOY $_{m}-$ DOY $_{n}$ & $121-151$ & $152-181$ & $182-212$ & $213-243$ & $244-273$ & 153 \\
Avg.ET & 71.22 & 136.72 & 141.63 & 160.45 & 101.40 & 611.42 \\
Avg. $P_{a}$ & 7.28 & 44.80 & 86.25 & 12.86 & 2.27 & 153.46 \\
Avg.GW & 63.94 & 91.92 & 55.38 & 147.59 & 99.13 & 457.96 \\
\hline
\end{tabular}

Avg.ET, Avg.P $P_{a}$, Avg.GW are calculated by average of ET METRIC values, $P_{a}$ values, $\mathrm{GW}$ values in the Xilin River Basin, respectively

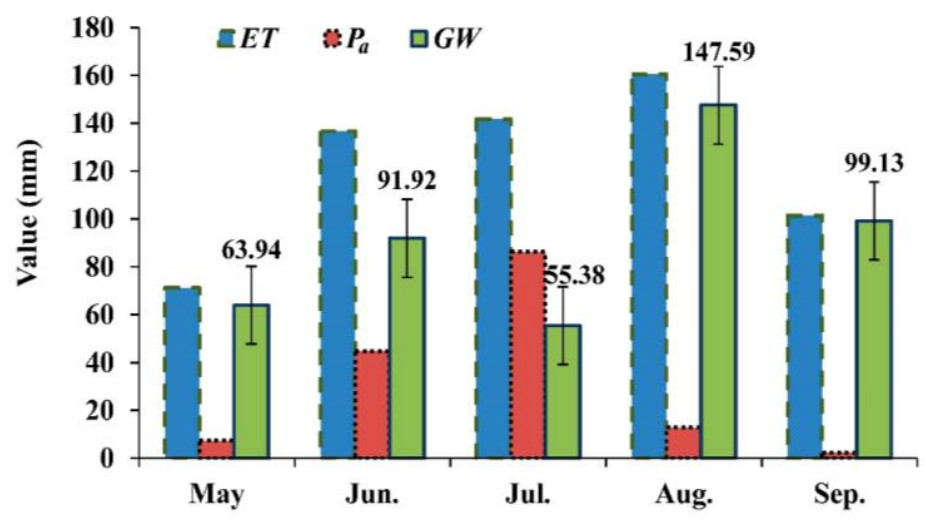

Figure 6. Laws of groundwater consumption in different periods (all parameters are in units of $\mathrm{mm})$

The values of ETMETRIC of the irrigated artificial grasslands during the crop growth season show a parabolic change of "first increasing, and then decreasing". With the increase in temperature, the value of ET is the maximum in July and August. The change in values of ET are highly consistent with the water consumption laws of crop growth (Tong et al., 2014). However, because of the influence of precipitation, the variation in the values of GW and ET change during different periods are significantly different, with details as follows: During the high-water consumption period of the crop growth season (July), precipitation is higher, while the values of GW of the irrigated artificial grasslands are relatively low. In addition, the value of precipitation in the study area is significantly lower in August, which results in the water consumption of the underlying surface being chiefly provided by regional groundwater resources, and the value of GW for the irrigated artificial grasslands is maximum. The above results show that the change in the values of GW are affected by not only the crop growth period on the underlying surface but also by weather factors such as precipitation, which cannot be ignored. 


\section{Conclusions}

In this study, the METRIC model was used for estimating the regional ET of the irrigated artificial grasslands in the Inner Mongolia typical steppe areas. The results were verified through the water balance method of eight irrigation monitoring points, with an MRE $=13.8 \%$. Combined with the previous remote sensing estimation of regional ET, the results show that the use of the METRIC model to estimate the ET of the Xilin River Basin, which is located in a typical steppe area, is reliable.

To analyze the consumption of local water resources, the spatial structure of the irrigated artificial grasslands are reclassified. The value of GW is introduced as the net consumption of local groundwater resources. Furthermore, the value of GW during the crop growth season in the Xilin River Basin is calculated. The crops planted over an area of $257.3 \mathrm{~km}^{2}$ of the irrigated artificial grasslands consumed a total of 118 million $\mathrm{m}^{3}$ of groundwater during the crop growth season. The net groundwater consumption of each of the farms, including that of Woyuan cow farm, Maodeng farm, Baiyinxile farm and Hezhongmumin farm, exceeded $400 \mathrm{~mm}$. These areas with high water consumption face difficulties in water resource management, particularly when there is no external water supply.

The water consumption of the underlying surface of a typical steppe is complex, and has several influencing factors such as climate and anthropogenic influence. In addition, its characteristic laws are variable at different time scales. In order to determine the impact of irrigation artificial grasslands on local groundwater resources, future studies performed on GW should be conducted based on monitoring data of groundwater level.

Acknowledgements. This work was supported by the special fund of State Key Laboratory of Simulation and Regulation of Water Cycle in River Basin (Grant NO. SKL2018TS01), and China Institute of Water Resources and Hydropower Research (Grant NO. MK2016J09).

\section{REFERENCES}

[1] Allen, R. G., Pereira, L. S., Raes, D., Smith, M. (1998): Crop Evapotranspiration: Guidelines for Computing Crop Water Requirements. - FAO Irrigation and Drainage Paper No. 56. FAO, Rome.

[2] Allen, R. G., Tasumi, M., Morse, A., Trezza, R., Wright, J. L., Bastiaanssen, W., Kramber, W., Lorite, I., Robison, C. W. (2007a): Satellite-based energy balance for mapping evapotranspiration with internalized calibration (METRIC) - applications. Journal of Irrigation and Drainage Engineering 133: 395-406.

[3] Allen, R. G., Tasumi, M., Trezza, R. (2007b): Satellite-based energy balance for mapping evapotranspiration with internalized calibration (METRIC) - model. - Journal of Irrigation and Drainage Engineering 133: 380-394.

[4] Allen, R. G., Pereira, L. S., Howell, T. A., Jensen, M. E. (2011): Evapotranspiration information reporting: I. Factors governing measurement accuracy. - Agricultural Water Management 98: 899-920.

[5] Allen, R. G., Burnett, B., Kramber, W., Huntington, J., Kjaersgaard, J., Kilic, A., Kelly, C., Trezza, R. (2013): Automated calibration of the METRIC-Landsat evapotranspiration process. - JAWRA Journal of the American Water Resources Association 49: 563-576.

[6] Bastiaanssen, W. G. M., Menenti, M., Feddes, R. A., Holtslag, A. A. M. (1998a): The surface energy balance algorithm for land (SEBAL). Part 1: Formulation. - Journal of Hydrology 212: 801-811. 
[7] Bastiaanssen, W. G. M., Pelgrum, H., Wang, J., Ma, Y., Moreno, J. F., Roerink, G. J., Wal, D. T. V. (1998b): A remote sensing surface energy balance algorithm for land (SEBAL). Part 2: Validation. - Journal of Hydrology 212: 213-229.

[8] Batnasan, N. (2003): Freshwater issues in Mongolia. - Proceeding of the National Seminar on IRBM in Mongolia, Ulaanbaatar.

[9] Bowen, I. S. (1926): The ratio of heat losses by conduction and by evaporation from any water surface. - Physical Review 27: 779-787.

[10] Cai, X., Xu, Z., Su, B., Yu, W. (2009): Distributed simulation for regional evapotranspiration and verification by using remote sensing (in Chinese with English abstract). - Transactions of the Chinese Society of Agricultural Engineering 25: 154-160.

[11] Chen, S. (2002): Study the land use/land cover change and cycle of Xilin River Basin by remote sensing and GIS (in Chinese). - University of Chinese Academy of Sciences (the Institute of Remote Sensing Applications), Beijing.

[12] de la Fuente-Sáiz, D., Ortega-Farías, S., Fonseca, D., Ortega-Salazar, S., Kilic, A., Allen, R. (2017): Calibration of METRIC model to estimate energy balance over a drip-irrigated apple orchard. - Remote Sensing 9. https://doi.org/10.3390/rs9070670.

[13] French, A. N., Hunsaker, D. J., Thorp, K. R. (2015): Remote sensing of evapotranspiration over cotton using the TSEB and METRIC energy balance models. Remote Sensing of Environment 158: 281-294.

[14] Gao, Y. C., Long, D., Li, Z. L. (2008): Estimation of daily actual evapotranspiration from remotely sensed data under complex terrain over the upper Chao River basin in North China. - International Journal of Remote Sensing 29: 3295-3315.

[15] González-Dugo, M., Gonzalez-Piqueras, J., Campos, I., Balbontín, C., Calera, A. (2012): Estimation of surface energy fluxes in vineyard using field measurements of canopy and soil temperature. - Remote Sensing and Hydrology (Proceedings of a symposium held at Jackson Hole, Wyoming, USA, September 2010) IAHS 352: 59-62.

[16] Howell, T. A., Schneider, A. D., Jensen, M. E. (1991): History of Lysimeter Design and Use for Evapotranspiration Measurements. - Lysimeters for Evapotranspiration and Environmental Measurements, ASCE, Honolulu, Hawaii, 23-25 July, pp. 1-9.

[17] Huang, Y., Feng, G. L., Dong, W. J. (2011): Temporal changes in the patterns of extreme air temperature and precipitation in the various regions of China in recent 50 years (in Chinese). - Acta Meteorologica Sinica 69: 125-136.

[18] Kalma, J. D., Mcvicar, T. R., Mccabe, M. F. (2008): Estimating land surface evaporation: a review of methods using remotely sensed surface temperature data. - Surveys in Geophysics 29: 421-469.

[19] Kang, S. Z. (2007): Conspectus of Agricultural Soil and Water Engineering (in Chinese). - Chinese Agricultural Press, Beijing.

[20] Khand, K., Kjaersgaard, J., Hay, C., Jia, X. (2017): Estimating impacts of agricultural subsurface drainage on evapotranspiration using the Landsat imagery-based METRIC model. - Hydrology 4. DOI: 10.3390/hydrology4040049.

[21] Lian, J., Huang, M. (2015): Evapotranspiration estimation for an oasis area in the Heihe River basin using Landsat-8 images and the METRIC model. - Water Resources Management 29: 5157-5170.

[22] Liou, Y.-A., Kar, S. (2014): Evapotranspiration estimation with remote sensing and various surface energy balance algorithms - a review. - Energies 7: 2821-2849.

[23] Long, D., Singh, V. P. (2013): Assessing the impact of end-member selection on the accuracy of satellite-based spatial variability models for actual evapotranspiration estimation. - Water Resources Research 49: 2601-2618.

[24] Lu, H. Y., Li, H. P., Gao, Z. Y., Wang, D. X., Wang, J. (2016): Water and land resources allocation model of pastoral area based on grassland ecological conservation (in Chinese with English abstract). - Transactions of the Chinese Society of Agricultural Engineering 32: 123-130. 
[25] Lu, H. Y., Li, H. P., Wang, J., Gao, Z. Y. (2018): Regulation model and application for water-land-forage-livestock balance in pastoral areas (in Chinese with English abstract). Transactions of the Chinese Society of Agricultural Engineering 34: 87-95.

[26] Mayer, D. G., Butler, D. G. (1993): Statistical validation. - Ecological Modelling 68: 2132.

[27] Menenti M (1993): Parameteraization of Land Surface Evaporation by Means of Location Dependent Potential Evaporation and Surface Temperature Range. - In: Bolle, H.-J., Feddes, R. A., Kalma, J. D. (eds.) Exchange Processes at the Land Surface for a Range of Space and Time Scales. Proceedings of an International Symposium Held at Yokohama, Japan, 13-16 July. IAHS Press, Wallingford, UK.

[28] Monteith, J. L., Unsworth, M. H. (2013): Microclimatology of Radiation: (iii) Interception by Plant Canopies and Animal Coats. - In: Monteith, J. L., Unsworth, M. H. (eds.) Principles of Environmental Physics (4th Ed.). Academic Press, Boston, pp. 111133.

[29] Morton, C. G., Huntington, J. L., Pohll, G. M., Allen, R. G., McGwire, K. C., Bassett, S. D. (2013): Assessing calibration uncertainty and automation for estimating evapotranspiration from agricultural areas using METRIC. - JAWRA Journal of the American Water Resources Association 49: 549-562.

[30] Niu, S. L., Jiang, G. M. (2004): Function of artificial grassland in restoration of degraded natural grassland and its research advance (in Chinese). - Chin. J. Appl. Ecol. 15: 16621666.

[31] Norman, J. M., Kustas, W. P., Humes, K. S. (1995): Source approach for estimating soil and vegetation energy fluxes in observations of directional radiometric surface temperature. - Agricultural and Forest Meteorology 77: 263-293.

[32] Numata, I., Khand, K., Kjaersgaard, J., Cochrane, M., Silva, S. (2017): Evaluation of Landsat-based METRIC modeling to provide high-spatial resolution evapotranspiration estimates for Amazonian forests. - Remote Sensing 9: 46.

[33] Paço, T. A., Pôças, I., Cunha, M., Silvestre, J. C., Santos, F. L., Paredes, P., Pereira, L. S. (2014): Evapotranspiration and crop coefficients for a super intensive olive orchard. An application of SIMDualKc and METRIC models using ground and satellite observations. - Journal of Hydrology 519: 2067-2080.

[34] Pedro-Monzonís, M., Solera, A., Ferrer, J., Estrela, T., Paredes-Arquiola, J. (2015): A Review of water scarcity and drought indexes in water resources planning and management. - Journal of Hydrology 527: 482-493.

[35] Qin, Z., Karnieli, A., Berliner, P. (2010): A mono-window algorithm for retrieving land surface temperature from Landsat TM data and its application to the Israel-Egypt border region. - International Journal of Remote Sensing 22: 3719-3746.

[36] Rana, G., Katerji, N. (2000): Measurement and estimation of actual evapotranspiration in the field under Mediterranean climate: a review. - European Journal of Agronomy 13: 125-153.

[37] Reyes-González, A., Kjaersgaard, J., Trooien, T., Hay, C., Ahiablame, L. (2017): Comparative analysis of METRIC model and atmometer methods for estimating actual evapotranspiration. - International Journal of Agronomy 2017: 1-16.

[38] Roerink, G. J., Su, Z., Menenti, M. (2000): S-SEBI: A simple remote sensing algorithm to estimate the surface energy balance. - Physics and Chemistry of the Earth, Part B: Hydrology, Oceans and Atmosphere 25: 147-157.

[39] Sheng, X. (2017): Handbook of Characteristic Values of Rivers and Lakes in Inner Mongolia Autonomous Region (in Chinese). - Inner Mongolia University Press, Inner Mongolia, China.

[40] Spiliotopoulos, M., Holden, N. M., Loukas, A. (2017): Mapping evapotranspiration coefficients in a temperate maritime climate using the METRIC model and Landsat TM. - Water 9: 23. 
[41] Su, Z. (2002): The surface energy balance system (SEBS) for estimation of turbulent heat fluxes. - Hydrology \& Earth System Sciences 6: 85-99.

[42] Su, Z., Yacob, A., Wen, J., Roerink, G., He, Y., Gao, B., Boogaard, H., van Diepen, C. (2003): Assessing relative soil moisture with remote sensing data: theory, experimental validation, and application to drought monitoring over the North China Plain. - Physics and Chemistry of the Earth, Parts A/B/C 28: 89-101.

[43] Taherparvar, M., Pirmoradian, N. (2018): Estimation of rice evapotranspiration using reflective images of Landsat satellite in Sefidrood irrigation and drainage network. - Rice Science 25: 111-116.

[44] Talsma, C. J., Good, S. P., Jimenez, C., Martens, B., Fisher, J. B., Miralles, D. G., McCabe, M. F., Purdy, A. J. (2018): Partitioning of evapotranspiration in remote sensingbased models. - Agricultural and Forest Meteorology 260-261: 131-143.

[45] Tasumi, M. (2003): Progress in operational estimation of regional evapotranspiration using satellite imagery. - Thesis (Ph.D.), University of Idaho, USA.

[46] Thornthwaite, C. W. (1948): An approach toward a rational classification of climate. Geographical Review 38: 55-94.

[47] Tong, C., Wu, J., Yong, S., Yang, J., Yong, W. (2004): A landscape-scale assessment of steppe degradation in the Xilin River basin, Inner Mongolia, China. - Journal of Arid Environments 59: 133-149.

[48] Tong, C. F., Li, H. P., Bai, B., Zheng, H. X., Wang, J., Yang, Y. S., Miao, H. L. (2014): Study on water requirement rule and optimization irrigation quota of alfalfa in Xilin River basin (in Chinese). - Chinese Agricultural Science Bulletin 2014(29): 188-191.

[49] Trezza, R., Allen, R. G., Tasumi, M. (2013): Estimation of Actual evapotranspiration along the middle Rio Grande of New Mexico using MODIS and Landsat imagery with the METRIC model. - Remote Sensing 5: 5397-5423.

[50] Wright, J. L. (1982): New evapotranspiration crop coefficients. - Journal of the Irrigation \& Drainage Division 108: 57-74.

[51] Xu, D., Liu, Y., Yang, D., Zhang, B. Z. (2015): Evapotranspiration scale effect and temporal-spatial scale expansion (in Chinese). - Science China Press, Beijing.

[52] Yamanaka, T., Kaihotsu, I., Oyunbaatar, D., Ganbold, T. (2007): Summertime soil hydrological cycle and surface energy balance on the Mongolian steppe. - Journal of Arid Environments 69: 65-79.

[53] Yang, D., Chen, H., Lei, H. (2010): Estimation of evapotranspiration using a remote sensing model over agricultural land in the North China Plain. - International Journal of Remote Sensing 31: 3783-3798.

[54] Zamani Losgedaragh, S., Rahimzadegan, M. (2018): Evaluation of SEBS, SEBAL, and METRIC models in estimation of the evaporation from the freshwater lakes (case study: Amirkabir dam, Iran). - Journal of Hydrology 561: 523-531. 